\title{
The Wounds of Experience
}

from the series The Pleasures of Psychoanalysis

Sorel Cohen

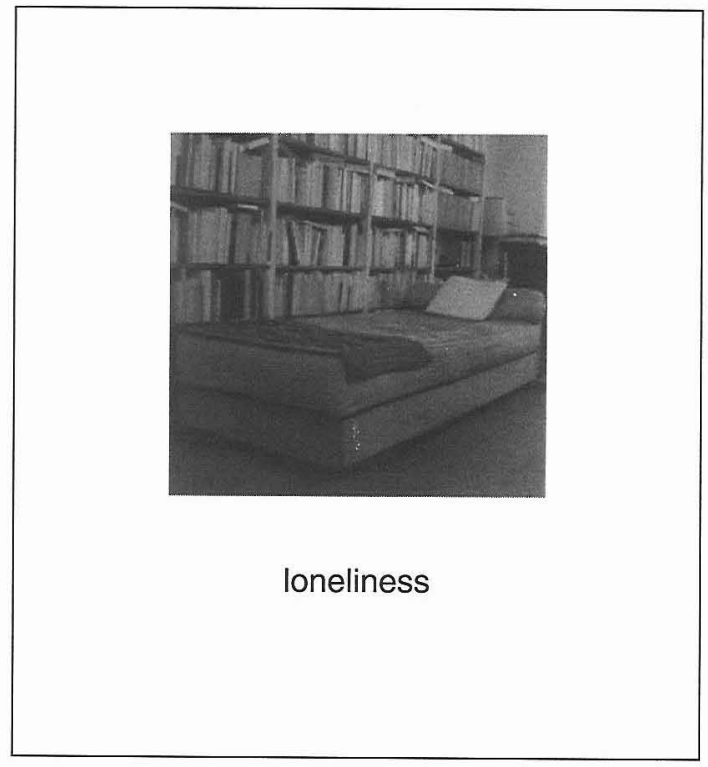


84 - Tessera
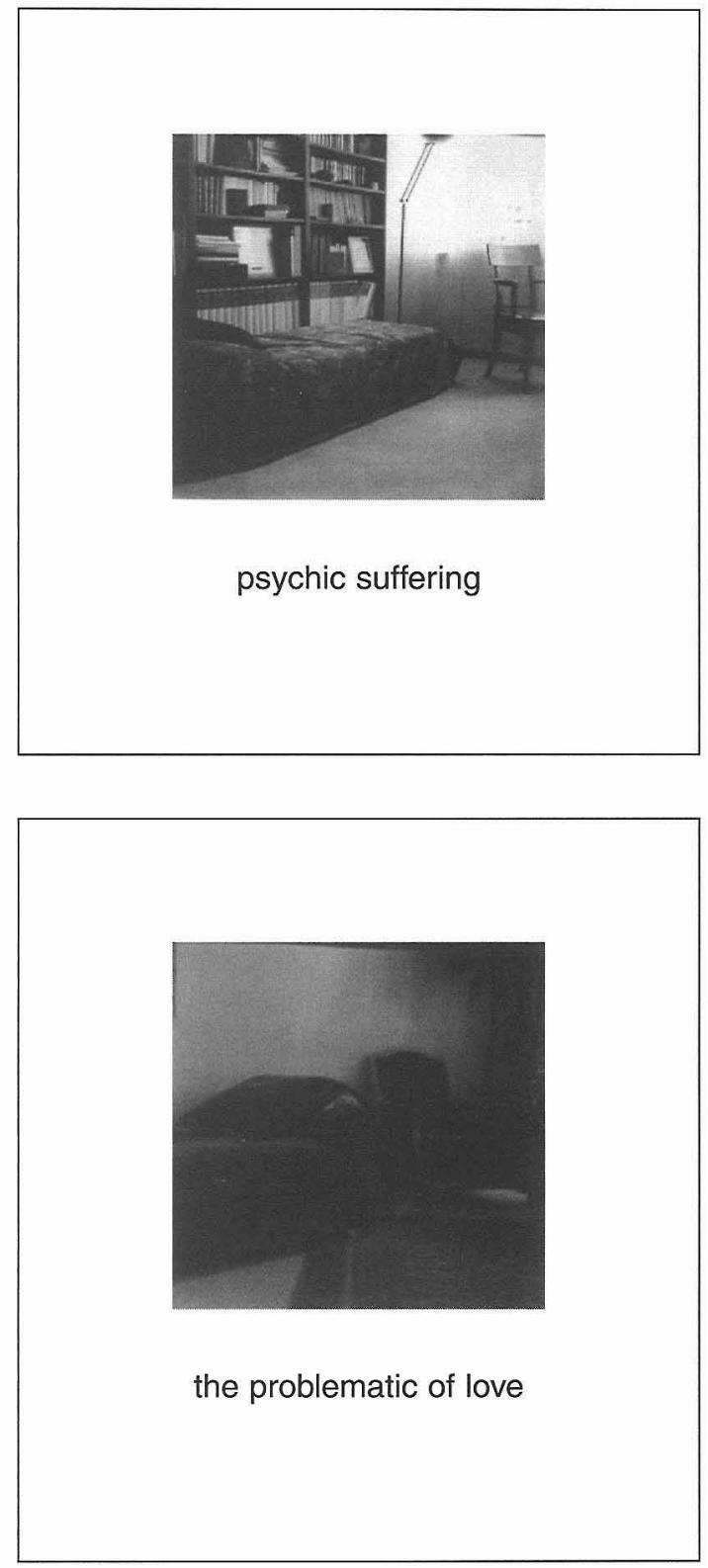
Wounds of Experience $\cdot 85$

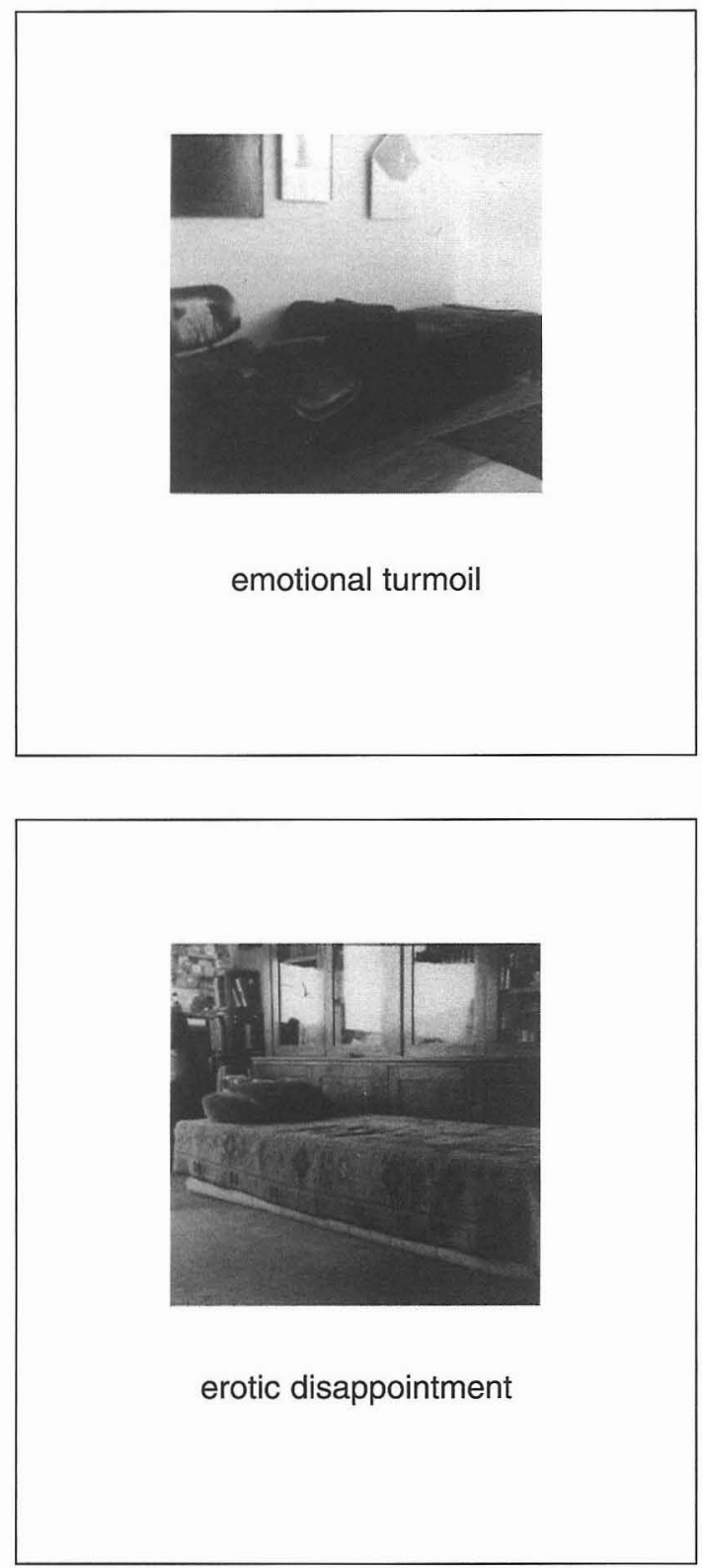



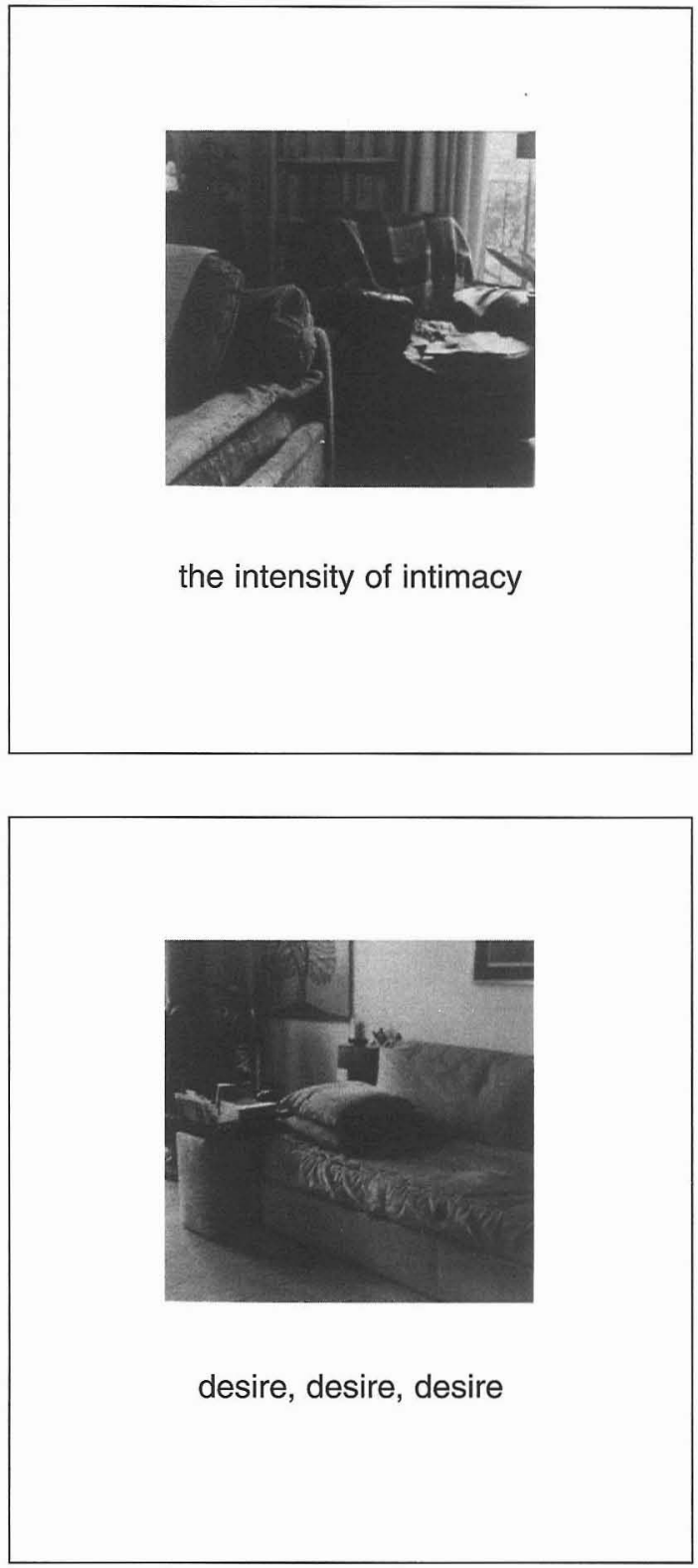